\title{
Evaluation of Fagopyrum esculentum Moench germplasm based on agro-morphological traits and the rutin and quercetin content of seeds under spring cultivation
}

\author{
Muhammad Rauf (D) Hyemyeong Yoon - Sukyeung Lee • Do Yoon Hyun • \\ Myung-Chul Lee $\cdot$ Sejong Oh $\cdot$ Yu -Mi Choi
}

Received: 29 July 2019/ Accepted: 4 February 2020/Published online: 21 February 2020

(C) The Author(s) 2020

\begin{abstract}
Buckwheat is an important grain crop known for its nutritional value and content of bioactive compounds, particularly rutin. In this study, we characterized diverse Fagopyrum esculentum Moench germplasm for the diversity of agro-morphological characteristics and the rutin and quercetin content in seeds under the spring cultivation. Of the 251 germplasm accessions assessed, 193 had red stems, 182 had a pale brown seed coat color, and 238 had ovate seeds. The times taken to reach $50 \%$ flowering and $80 \%$ maturity ranged from 38-45 to 73-95 days, respectively. The 1000-seed weight (TSW) varied from 21 to $42 \mathrm{~g}$. Overall, the content of rutin and quercetin ranged from $7.22-47.86$ to $0-1.22 \mathrm{mg} / 100 \mathrm{~g}$ DW, respectively. The number of days to flowering and maturity showed negative correlations with TSW and rutin and quercetin content. However, we found that at 73-80 days after sowing, early-maturing germplasm had significantly higher mean rutin content than either intermediate-or late-maturing germplasm.
\end{abstract}

Electronic supplementary material The online version of this article (https://doi.org/10.1007/s10722-020-00899-3) contains supplementary material, which is available to authorized users.

M. Rauf · H. Yoon - S. Lee - D. Y. Hyun - M.-C. Lee · S. Oh · Y.-M. Choi $(\square)$

National Agrobiodiversity Center, National Institute of Agricultural Sciences, Rural Development

Administration, Jeonju 54874, Republic of Korea

e-mail: cym0421@korea.kr
The TSW weight showed a positive correlation with the content of rutin and quercetin. We identified promising accessions based early maturity ( $<80$ days), higher seed weight $(\geq 35 \mathrm{~g}$ ) and higher content of rutin ( $\geq 35 \mathrm{mg} / 100 \mathrm{~g} \mathrm{DW})$ and quercetin $(\geq 1 \mathrm{mg} / 100 \mathrm{~g} \mathrm{DW}$ ). These accessions will help to enhance grain yield and the rutin and quercetin content in existing buckwheat cultivars for spring cultivation.

Keywords Agro-morphological traits · Evaluation · Fagopyrum esculentum germplasm · Quercetin · Rutin

\section{Introduction}

Buckwheat is a dicotyledonous grain crop plant in the family Polygonaceae, which is known for its high nutritional value and bioactive components, particularly the content of rutin and quercetin. Two commonly grown buckwheat species are Fagopyrum esculentum Moench (common buckwheat) and Fagopyrum tataricum Gaertn (tartary buckwheat). Interestingly, although its common name includes the word "wheat," these plants are taxonomically unrelated to the traditionally cultivated wheat and are generally considered pseudo-cereals (Joshi and Rana 1995). Buckwheat has a comparatively rapid life cycle and reaches maturity within 3-4 months (Arduini et al. 2016). Moreover, it shows considerable adaptability to diverse ecological environments and can be 
grown on a wide range of soils under various climatic conditions ( $\mathrm{Li}$ and Zhang 2001). It is grown worldwide throughout Asia, Europe, the United States (USA), Brazil, Canada, Australia, and South Africa (Kiprovski et al. 2015), although the main areas of cultivation are in East Asian countries (Wiczkowski et al. 2014). Tartary buckwheat is mainly cultivated in Asia, whereas common buckwheat is grown more extensively in virtually all grain crop-producing countries (Chen et al. 2018).

Buckwheat is a gluten-free grain crop that can be used in the diets of patients with celiac disease (Mazza and Oomah 2005; Sytar et al. 2016). In addition, compared with other cereals, buckwheat is characterized by a relatively higher nutritional value. Biochemical analyses of buckwheat germplasm have indicated that seeds of these plants are an excellent source of starch, proteins, fats, dietary fiber, vitamins, minerals, and phenolic components (Bobkov 2016). The protein content in buckwheat is higher than other cereals (Sytar et al. 2018), and buckwheat proteins are particularly rich in lysine, arginine, and aspartic acid (Bobkov 2016). Lysine plays an important role in protein biogenesis but cannot be synthesized by mammals (Tome and Bos 2007), and therefore must be obtained from alternative dietary sources ( $\mathrm{Yu}$ and Tian 2018). Although cereals are typically deficient in lysine (Ferreira et al. 2005), the groats of buckwheat contain reasonable amounts of lysine (Rout and Chrungoo 1999; Sytar et al. 2016). Moreover, in comparison with the major cereal crops, buckwheat also contains a considerable quantity of flavonoids. Six flavonoids have been identified in buckwheat, namely, rutin, orientin, vitexin, quercetin, isovitexin, and isoorientin, of which rutin, also known as vitamin $\mathrm{P}$, is the major flavonoid (Park et al. 2000, 2004; Ghiasi et al. 2012; Bobkov 2016; Sytar et al. 2016; Ganeshpurkar and Saluja 2017). Rutin has beneficial effects on cardiovascular diseases, and notably reduces the risk of arteriosclerosis (Kreft et al. 2003). Of the two most widely cultivated buckwheats, tartary buckwheat has higher rutin content than common buckwheat (Chauhan et al. 2010; Gupta et al. 2012); however, on account of its bitter taste, tartary buckwheat is rarely consumed. Korea, China, and Japan are the main growing areas of common buckwheat due to its use as a functional food (Kim et al. 2001; Jung et al. 2015).
Flavonoids are secondary metabolites that comprise a large group among the polyphenolic components of plants (Mathesius 2018) and are known to play important roles in the growth and development of plants and in protection against UV light and diseases (Panche et al. 2016; Vicente and Boscaiu 2018). Differences in the morphology and coloration of plant parts, such as the color of flowers, stems, leaves, and seeds and the shape of seeds, can serve as valuable diagnostic traits for the selection of genotypes with higher levels of phenolic components (Klykov et al. 2016). Research of various buckwheat species have shown that color visual assessment of the vegetative parts is a marker for selection of buckwheat genotypes with high anthocyanin and content of rutin (Sytar et al. 2016). However, variations in the color of plant vegetative organs and content of flavonoids often depend upon variety, area of collection, and ecological conditions (Fabjan et al. 2003; Podolska 2016). Successful crop improvement requires a continuous supply of genetic diversity that includes novel or enhanced variability (Dwivedi et al. 2016). In this regard, germplasm collections and the genetic diversity available in various buckwheat germplasms could represent valuable sources of material for altering certain specific aspects of plant metabolic chemistry (Matsuri et al. 2008).

Despite the high nutritional value of buckwheat, there has to date been limited research on the morphological diversity of common buckwheat germplasm associated with flavonoid content. Buckwheat shows a wide diversity in growth traits related to seed size and shape, seed coat and flower color, grain yield, and the content of phenolic components. Flavonoid contents could vary based on varietal variability (Oomah et al. 1996; Kalinová and Dadáková 2006; Brunori et al. 2009; Qin et al. 2010; Kiprovski et al. 2015; Raina and Gupta 2015), sowing time (Omidbaigi and Mastro 2004; Jinfeng et al. 2010; Hyun et al. 2018), location (Bai et al. 2015), growth stages (Bystricka et al. 2014), environmental factors such as UV radiation, light (Suzuki et al. 2005; Kim et al. 2006; Nam et al. 2018) and area of collection (Seo et al. 2013; Bai et al. 2015; Yu et al. 2019). Oomah et al. (1996) reported that variation is phenolic acids in buckwheat is mainly due to cultivar, seasonal effects, and their interaction, whereas growing location has no effect. Cultivation season is an important factor determining dry matter production, as different 
buckwheat genotypes show differing responses to environmental change, and shift their growth from vegetative to reproductive in response to specific environmental cues. In Korea, most of the cultivated buckwheat varieties are of the fall type and do not set seed when planted in the spring season. Given that grain yield is generally lower in the spring season than in fall cultivation. Hyun et al. (2018) reported a $26 \%$ reduction in seed weight and a $51 \%$ reduction in rutin content under spring cultivation as compared to fall cultivation. Despite the numerous studies on buckwheat, there is still a lack of information on the comparison of morphological traits and flavonoid content of common buckwheat from a different origin. Therefore, it would be desirable to determine whether diverse germplasm sources could be exploited to enhance cultivated buckwheat grain yields and flavonoid contents in the spring season. Thus, in this study, we aimed to characterize diverse common buckwheat germplasm with respect to agro-morphological traits and the major flavonoids components (rutin and quercetin) during the spring season and to study the relationships between agro-morphological traits and the content of rutin and quercetin in seeds.

\section{Materials and methods}

In this study, we evaluated 251 common buckwheat germplasm accessions held in the collection of the National Genetic Resource Center (the RDA gene bank), Rural Development Administration (RDA), Jeonju, The Republic of Korea. The germplasm collection includes 208 accessions from Korea, 10 from Japan, 9 from Russia, 6 from China, 4 from both Pakistan and Ukraine, 3 from both the Czech Republic and India, and 1 from each of Belarus, Bhutan, Canada, and Nepal (Table 1). Two Korean commercial common buckwheat varieties "Yangjeol-2" and "Dawon" were included as a control. During the spring season, 30 seeds per accessions were sown using drill planting methodology in the field of the National Institute of Agricultural Sciences, RDA, Jeonju, maintaining the crop density at $20 \mathrm{~cm} \times 40$ $\mathrm{cm}$. The field was fertilized with N: P: K @ 21: 17: $17 \mathrm{~kg} 10 \mathrm{a}^{-1}$, respectively. For other cultural managements practices, the recommended cultivation method of RDA was followed (RDA 2012a, b). At the time of flowering, a net-house was installed for each accession and 3 bumblebees per net-house were release to facilitate pollination. The germplasm was evaluated in terms of agro-morphological traits and the content of rutin and quercetin of seeds.

Evaluation of agro-morphological traits

Morphological characterization of germplasm was performed based on stem color, seed coat color, and seed shape. Stem color was recorded for green, pale green, pale red, red and dark red. Seed coat color was recorded for white, grey, pale brown, dark brown and black. Seed shape was recorded for Oval, egg-shaped (Ovate), triangular-type and winged-form (RDA 2012a, b). Agronomic characterization was performed based on the number of days to flowering, number of days to maturity, and 1000-seed weight (TSW). Days to flowering were counted from the date of sowing to the stage where over $50 \%$ of flowers had opened, whereas days to maturity were counted from the date of sowing to $80 \%$ seed pods turned into black color. One hundred seeds were randomly selected from bulked seeds of each plot, weighed after drying and multiplied by 10 to calculate TSW (ISTA 2019). The TSW was measured in in three biological replicates.

Evaluation of the rutin and quercetin content of seeds

\section{Reagents}

All chemicals used in this study were of HPLC grade. Methanol $(\mathrm{MeOH})$, ethanol $(\mathrm{EtOH})$, and acetonitrile $\left(\mathrm{CH}_{3} \mathrm{CN}\right)$ were purchased from Thermo Fisher Scientific (Seoul, South Korea), HPLC-Grade water was purchased from Avantor Performance Materials (Suwon-Si, South Korea). Flavonoid standards (rutin and quercetin) at purity of $>99 \%$ HPLC grade were purchased from Extra Synthase (Genay, France).

\section{Extraction of flavonoid compounds}

We prepared 2 samples per genotype for HPLC analysis. For each sample, seeds from 10 randomly selected plants were ground into a fine powder, of which $100 \mathrm{mg}$ sample was added to $2-\mathrm{mL}$ microcentrifuge tubes and extracted with $1 \mathrm{~mL}$ of $\mathrm{MeOH}$ containing $10 \%$ phosphoric acid $[0.1 \%(\mathrm{v} / \mathrm{v})]$. The mixture was vigorously vortexed for $5 \mathrm{~min}$ at room 
Table 1 List of common buckwheat (Fagopyrum esculentum) accessions used in this study

\begin{tabular}{|c|c|c|}
\hline Country $^{\mathrm{a}}$ & $\begin{array}{l}\text { No. of } \\
\text { accessions }\end{array}$ & Accession number \\
\hline KOR & 208 & 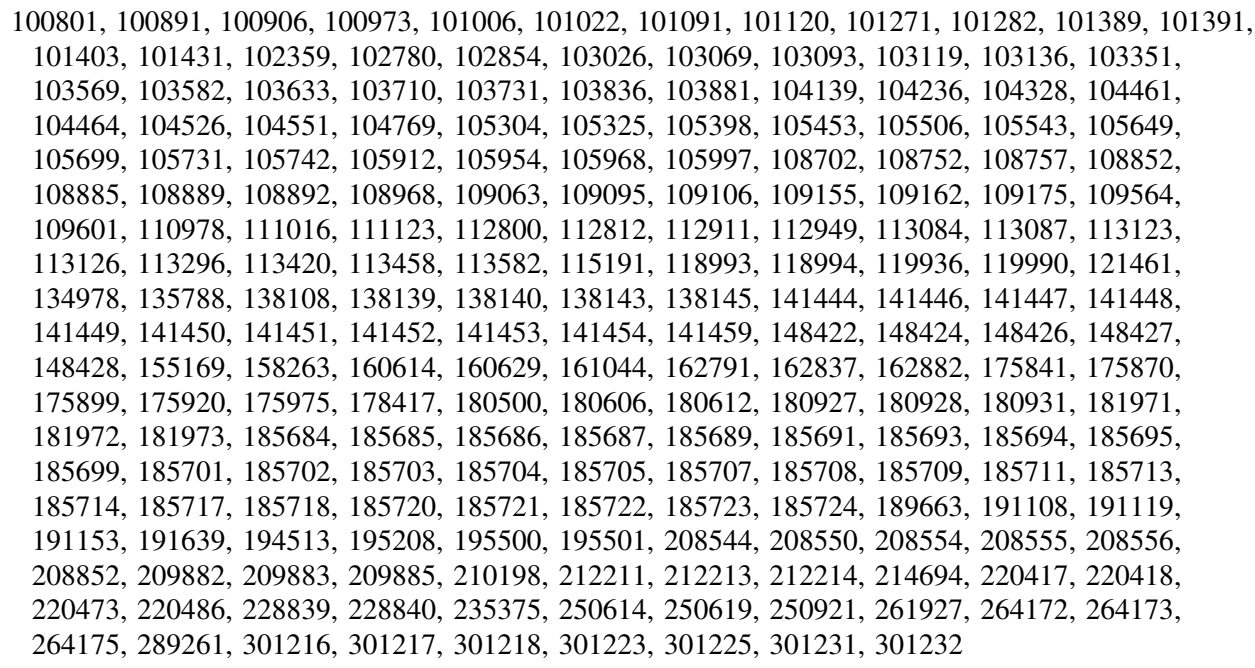 \\
\hline JPN & 10 & $28843,28844,221968,250613,250617,250626,261921,261923,302328,302329$ \\
\hline RUS & 9 & $179841,179843,179844,199282,199286,200686,225054,278144,278145$ \\
\hline $\mathrm{CHN}$ & 6 & $187869,187871,250624,261925,289118,310514$ \\
\hline PAK & 4 & $301212,301213,310518,310519$ \\
\hline UKN & 4 & $199279,199280,209496,225055$ \\
\hline CZE & 3 & $250622,288928,288929$ \\
\hline IND & 3 & $301211,310472,310517$ \\
\hline BLR & 1 & 179846 \\
\hline BTN & 1 & 261914 \\
\hline CAN & 1 & 302264 \\
\hline NPL & 1 & 310516 \\
\hline Control & 2 & Dawon, Yangjeol-2 \\
\hline
\end{tabular}

${ }^{a}$ BLR, Belarus; BTN, Bhutan; CAN, Canada; CHN, China; CZE, Czech Republic; IND, India; JPN, Japan; KOR, Korea; NPL, Nepal; PAK, Pakistan; RUS, Russia; UKN, Ukraine

temperature and then incubated at $37{ }^{\circ} \mathrm{C}$ for $3 \mathrm{~h}$, with vortexing for $5 \mathrm{~min}$ at hourly intervals. Following incubation, the extracts were centrifugation at $12,000 \times g$ for $10 \mathrm{~min}$ and the resulting supernatants were filtered using disposable syringe filters (PTFE, $0.45 \mu \mathrm{m}$, hydrophilic; Advantec, Tokyo, Japan). Flavonoid standards were prepared as $100 \mathrm{ppm}$ $(0.1 \mathrm{mg} / \mathrm{mL})$.

\section{HPLC analysis}

Identification and quantification of flavonoid components (rutin and quercetin) were based on the methods described by Kim et al. (2008). The extracts obtained were analyzed using an Agilent 1200 series HPLC system (Agilent Technologies, USA). Flavonoids were separated using a Capcell PAK C18 column $(4.6 \times 250,5 \mu \mathrm{m}$; Shiseido, Tokyo, Japan). The temperature of the oven was set at $40{ }^{\circ} \mathrm{C}$, the injection volume used was $10 \mu \mathrm{L}$, and absorbance was monitored at $350 \mathrm{~nm}$. The mobile phase, consisting of a mixture of solvent A (MeOH:water:acetic acid [5:92.5:2.5, (v/v/v)] and solvent B (MeOH:water:acetic acid [92.5:2.5:2.5, (v/v/v)], was delivered at a rate of $1.0 \mathrm{~mL} / \mathrm{min}$. The mobile phase initially comprised $10 \%$ solvent B ( $0 \mathrm{~min})$, and thereafter was altered via linear gradient of $36 \%$ solvent $\mathrm{B}$ for $27 \mathrm{~min}, 60 \%$ solvent B for $32 \mathrm{~min}, 60 \%$ solvent B for 
$35 \mathrm{~min}, 10 \%$ solvent B for $35.1 \mathrm{~min}$ and $10 \%$ solvent $\mathrm{B}$ for $40 \mathrm{~min}$. The analysis was replicated two times and the content of rutin and quercetin was quantified using the following formula based on the peak areas and concentration of samples and representative standard compounds (Hyun et al. 2018)

$x=\frac{\text { sample area }}{\text { STD area }} \times \frac{0.1 \mathrm{mg}}{1 \mathrm{~mL}} \times \frac{1 \mathrm{~mL}}{0.1 \mathrm{~g}}$.

All contents were expressed in terms of milligrams per $100 \mathrm{~g}$ dry weight $(\mathrm{mg} / 100 \mathrm{~g} \mathrm{DW})$. The analysis of flavonoid was conducted in two biological replicates.

\section{Statistical analysis}

Replicated data were subjected to statistical analysis by the application of a $t$ test and one-way analysis of variance (ANOVA) at the 5\% probability level, using Statistix ver. 8.1 software (McGraw-Hill 2008). Principal component (PCA) and correlation analyses were performed in RStudio version 1.2.1335 (RStudio Team 2019).

\section{Results and discussion}

Evaluation of agro-morphological traits

The results of agro-morphological characterization and the corresponding frequency distributions are presented in Table 2. In the case of stem color, we found that red stem color was predominant in $76.89 \%$ (193) of the accessions assessed, whereas $23.11 \%$ (58) of accessions had a pale green stem color. Recently, Kapoor et al. (2018) reported red and pink stem color in buckwheat germplasm, which can probably be attributed to the accumulation of anthocyanins, an assumption supported by the findings of Fang et al. (2019), who reported differences in anthocyanin pathways in the cotyledons and flowers of red- and green-stemmed buckwheat. With regards to seed coat color, we found that $72.51 \%$ (182) of accessions had a pale brown color, whereas dark brown seed coats were observed in $27.49 \%$ of (69) of accessions. In contrast, Raina and Gupta (2015) have previously found brownish yellow, brown, dark brown, gray, and black seed coat colors among common buckwheat germplasms. Similarly, in the common buckwheat germplasm examined by Baniya et al. (1995), the seeds of more than $50 \%$ of accessions were grayishblack, $36 \%$ were brown, and the remainders were either black or gray. Furthermore, we observed eggshaped (ovate) seeds in $94.83 \%$ (238) of accessions, triangular seeds in $2.79 \%$ (7), and winged-form seeds in $2.39 \%$ (6). Our results in this regard are consistent with the findings of Kapoor et al. (2018), who reported triangular- and ovate-type seeds in their study. In contrast, Raina and Gupta (2015) observed only triangular-type seeds in their evaluation of 68 common buckwheat germplasm accessions for seed rutin content. In a further study reported by Baniya et al. (1995), $92 \%$ of the germplasm assessed had smooth-type seeds, whereas $8 \%$ had winged-form seeds. Collectively, these results indicate that, in terms of morphological traits, common buckwheat germplasm is characterized by considerable diversity, which could be a consequence of outcrossing, given that common buckwheat is a self-incompatible species in which fertilization occurs via insect-mediated cross-pollination (Iwata et al. 2005; Grahic et al. 2016).

With respect to agronomic characterization, we found that the $50 \%$ flowering ranged from 38 to 46 days, averaging about 38 days. In terms of frequency distribution, $94 \%$ of accessions took $38-40$ days to reach the $50 \%$ flowering stage, $3 \%$ took 41-43 days, and 3\% took 44-46 days (Fig. 1a). In the comparison of collecting countries, we observed that germplasm accessions collected from Japan, Russia, China, Ukraine, Czech Republic, Belarus, Bhutan, Canada, and Nepal reached to 50\% flowering in 38 days, whereas germplasm collected from India and Korea took 38-35 and 38-36 days for 50\% flowering, respectively. The control varieties took 41 days for $50 \%$ flowering. Similarly, the time taken to reach $80 \%$ of maturity ranged from 73 to 95 days, with a mean of 89 days. In terms of frequency distribution, only $9.2 \%$ of accessions showed early maturation in the range of 73-80 days, whereas 50\% took 81-90 days to reach maturity and $41 \%$ took 91-95 days (Fig. 1b). The range of days to maturity in different collecting countries was: Japan (73-94), China (73-88), Ukraine (73-95), Czech Republic (75-82), Russia (75-94), Korea (75-95), Canada (80), Bhutan (82), Belarus and Nepal (88), Pakistan and India (88-95). In control varieties, days to maturity raged from 84 to 88 days. 


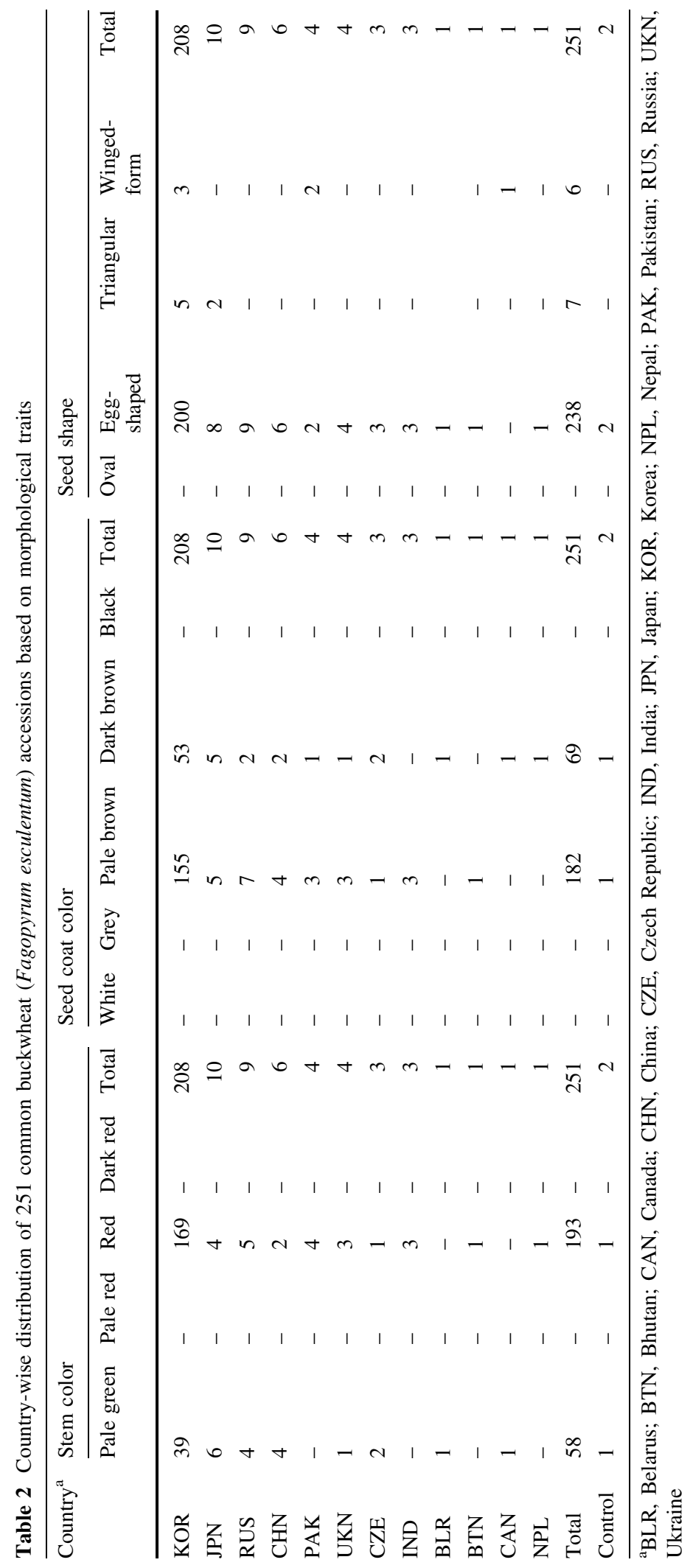


The 1000-seed weight (TSW) ranged from 21 to $42 \mathrm{~g}$ with a mean of $26.3 \mathrm{~g}$. This range of TSW in our study is agreement with previous reported TSW in common buckwheat germplasm: 10.2-31.8 g (Baniya et al. 1995), 12-35 g (Grubben and Siemonsma 1996), 13.85-37.19 (Cepková et al. 2009), 24.50-33.08 g (Kapoor et al. 2018), 20.9-26.4 g (Jung et al. 2015). In term of frequency distribution $48 \%$ germplasm had TSW ranged from 20 to $25 \mathrm{~g}, 44 \%$ had $26-30 \mathrm{~g}, 7 \%$ had $31-35$ and only $1 \%$ germplasm had above $35 \mathrm{~g}$ (Fig. 1c). The range of TSW according to collecting counties was Korea (21-41 g), Bhutan (22.3 g), Russia (22.7-35 g), India (23.7-25.7 g), China (23.7$34.3 \mathrm{~g}$ ), Japan (24.7-42 g), India (25.3-25.7 g), Pakistan (25-30 g), Ukraine (25.3-30 g), Czech Republic (28.7-32.7 g), Belarus (32 g), Nepal (33.3 g), Canada $(35.3 \mathrm{~g})$. The germplasm accessions with the highest TSW were found in Korean and Japanese collections. In control varieties, TSW ranged from 28 to $32.7 \mathrm{~g}$.

Evaluation for rutin and quercetin content

The HPLC peaks of standard and quantified rutin and quercetin content are shown in Supplementary Fig. S1. We found that the rutin content of seed was typically higher than that of quercetin, indicating that rutin is the major flavonoid in buckwheat seeds. These observations are consistent with the findings of Bai et al. (2015) and Raina and Gupta (2015), who reported rutin as the major flavonoid in buckwheat seeds. Overall, we found that the rutin content in common buckwheat seeds ranged from 7.22 to $47.86 \mathrm{mg} / 100 \mathrm{~g}$ DW, averaging $18.52 \mathrm{mg} / 100 \mathrm{~g}$ DW. In terms of frequency distribution, $69 \%$ of the germplasm had rutin content in the range of $11-20 \mathrm{mg} / 100 \mathrm{~g} \mathrm{DW}$, followed by $25 \%$ in the range of $21-30 \mathrm{mg} / 100 \mathrm{~g} \mathrm{DW}$ and $4 \%$ in the range of $31-40 \mathrm{mg} / 100 \mathrm{~g}$ DW. In contrast, only $2 \%$ of germplasm had higher rutin content in the range of 41-50 mg/100 g DW (Fig. 2a). This range of rutin concentrations is in good accordance with earlier findings (Kitabayashi et al. 1995; Fabjan et al. 2003; Brunori and Vegvari 2007; Brunori et al. 2010; Raina and Gupta 2015; Kiprovski et al. 2015). In our results, the range of rutin according to collecting countries was: India (7.22-14.20 mg/100 g DW), Korea (8.64-47.86 mg/100 g DW), China (8.75-19.61 mg/
100 g DW), Pakistan (12.35-17.66 mg/100 g DW), Canada (14.47 mg/100 g DW), Russia (14.68$38.96 \mathrm{mg} / 100 \mathrm{~g}$ DW), Ukraine (17.35-22.36 mg/ $100 \mathrm{~g}$ DW), Nepal (17.45 mg/100 g DW), Japan (19.24-38.22 mg/100 g DW), Czech Republic (21.39-46.75 mg/100 g DW), Bhutan (25.80 mg/ $100 \mathrm{~g} \mathrm{DW})$, Belarus (45.54 mg/100 g DW). In control varieties, the rutin content ranged from 11.64 to $17.82 \mathrm{mg} / 100 \mathrm{~g} \mathrm{DW}$ (Table 3). The mean content of rutin was in the order of Belarus $>$ Czech Republic $>$ Japan $>$ Bhutan $>$ Russia $>$ Ukraine $>$ Korea $>$ Nepal $>$ Pakistan $>$ Canada $>$ China $>$ India. In contrast, in a study reported by Minami et al. (2001), a wide variation in rutin content was observed among common buckwheat accessions of Japanese, Chinese, Nepalese and European origin and some of the Nepalese accessions were considered to be useful breeding material. Recently, Yu et al. (2019) reported a variation of rutin content in diverse tartary buckwheat germplasm. In their study the content of rutin was in the order of Nepal $>$ Bhutan $>$ Japan $>$ China $>$ Pakistan $>$ Slovenia $>$ Indian. Similarly, Park et al. (2005) reported the content of rutin in tartary buckwheat germplasm in the order of Bhutan $>$ Slovenia $>$ China $>$ Pakistan $>$ Nepal $>$ Japan $>$ India. Similarly, higher rutin content was reported in accessions collected from Nepal than lines collected elsewhere (Kitabayashi et al. 1995).

Likewise, the content of quercetin ranged from 0 to $1.22 \mathrm{mg} / 100 \mathrm{~g} \mathrm{DW}$, averaging $0.35 \mathrm{mg} / 100 \mathrm{~g}$ DW. In terms of frequency distribution, we found that quercetin content was not detected in $20 \%$ germplasm, whereas $74 \%$ of germplasm had seed content in the range of $0.2-0.6 \mathrm{mg} / 100 \mathrm{~g} \mathrm{DW}$, followed by $5 \%$ with content in the range of $0.7-1.0 \mathrm{mg} / 100 \mathrm{~g}$ DW. Only $1 \%$ of germplasm had quercetin content greater than $1.0 \mathrm{mg} / 100 \mathrm{~g} \mathrm{DW}$ (Fig. 2b). The range of quercetin content appears to be higher than that reported previously (Fabjan et al. 2003; Qin et al. 2010; Wiczkowski et al. 2014; Bai et al. 2015; Kalinová et al. 2019). In contrast to the results obtained in the present study, Qin et al. (2010) detected quercetin in only one of the 18 common buckwheat accessions they evaluated for phenolic components. Similarly, Bai et al. (2015) and Fabjan et al. (2003) failed to detect quercetin in the seeds of the common buckwheat germplasm they examined. The range of quercetin according to collecting countries was: Belarus 


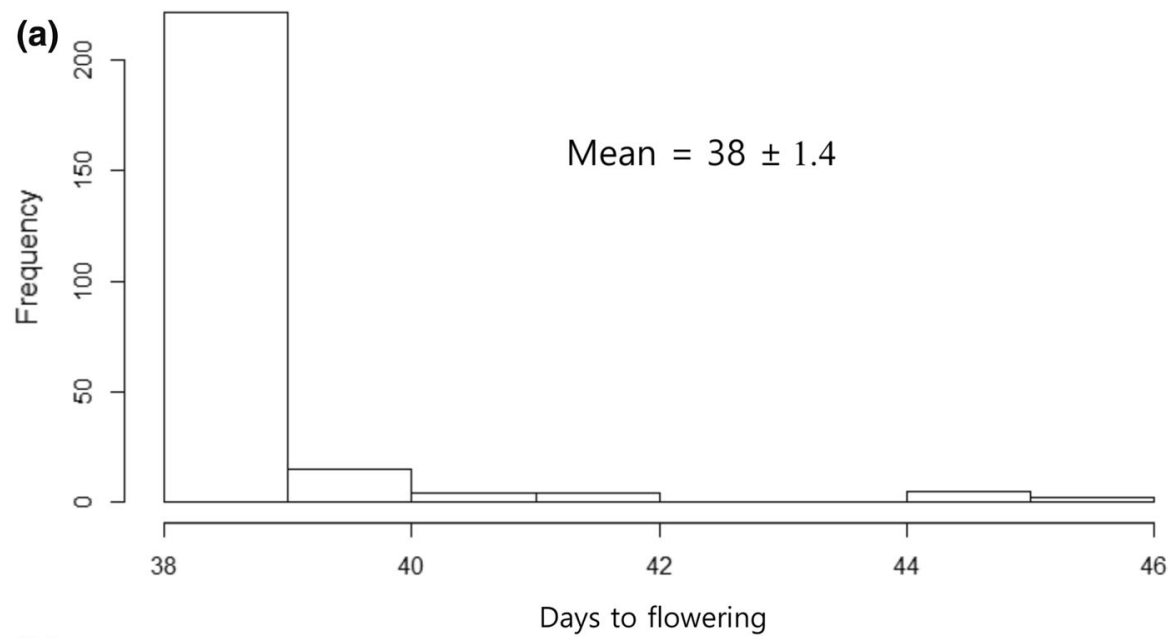

(b)
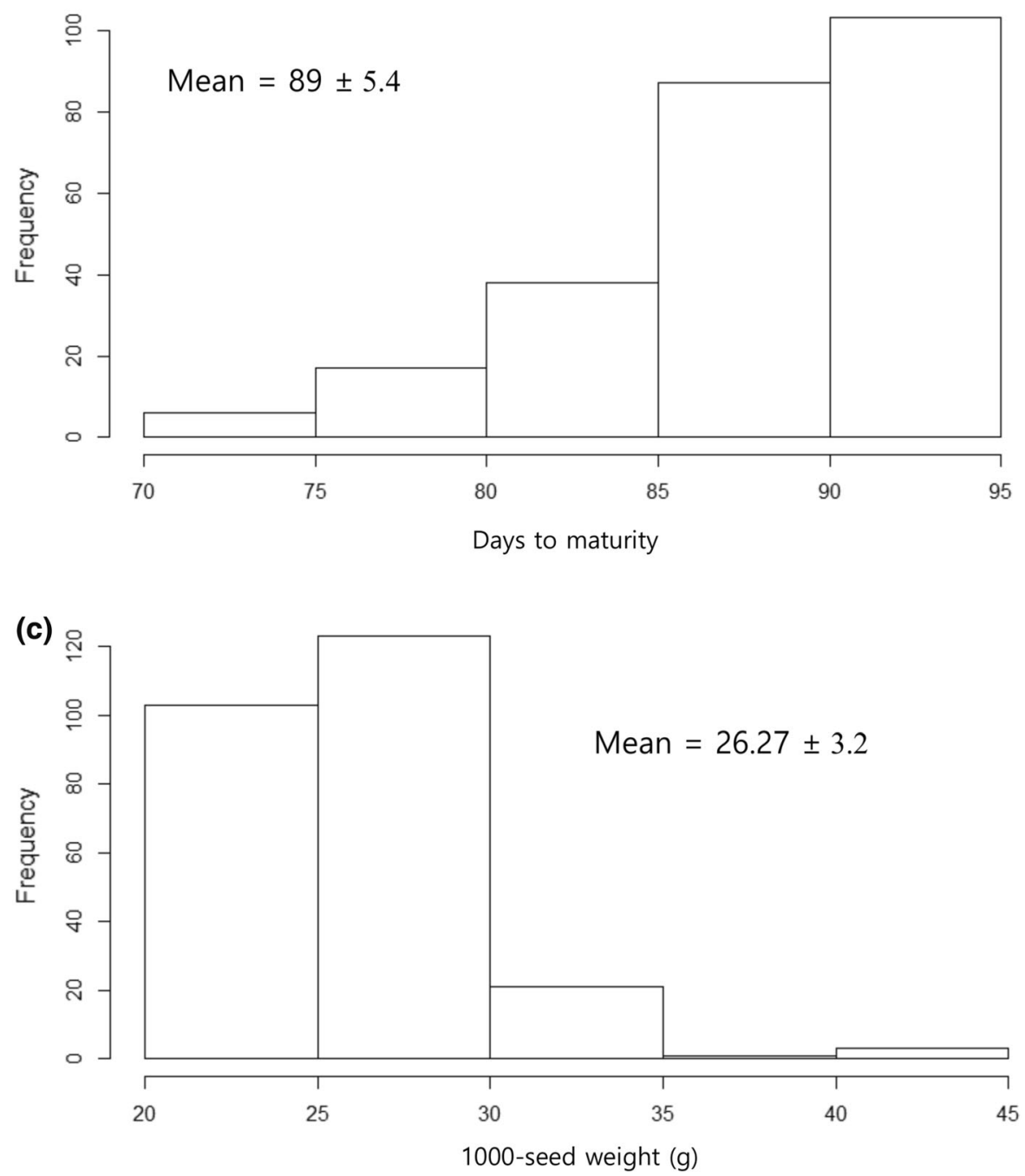
4Fig. 1 Frequency distribution of agronomic traits in 251 accessions of common buckwheat (Fagopyrum esculentum): a days to flowering, b days to maturity, c 1000-seed weight (g)

(1.22 mg/100 g DW), Korea (0-1.15 mg/100 g DW), Russia (0-1.05 mg/100 g DW), China (0-0.91 mg/ $100 \mathrm{~g}$ DW), Ukraine (0-0.52 mg/100 g DW), Japan (0.22-0.70 mg/100 g DW), India (0.24-0.33 mg/ $100 \mathrm{~g}$ DW), Pakistan (0.30-0.55 mg/100 g DW), Nepal (0.31 mg/100 g DW), Canada $(0.35 \mathrm{mg} / 100 \mathrm{~g}$ DW), Czech Republic (0.38-0.69 mg/100 g DW), Bhutan $(0.53 \mathrm{mg} / 100 \mathrm{~g} \mathrm{DW})$. In control varieties, the quercetin content ranged from 0.24 to $0.36 \mathrm{mg} / 100 \mathrm{~g}$
DW (Table 3). These results indicate that buckwheat has a wide range of diversity in flavonoid content and genotype and area of the collection are important factors to be considered in evaluating buckwheat for high flavonoid content.

Agro-morphological characterization for rutin and quercetin content

With regards to morphological traits, although we found differences in the rutin and quercetin content of germplasm with pale green and red stem color, these were non-significant. The mean rutin content (20.35 mg/100 g DW) of germplasm with pale green

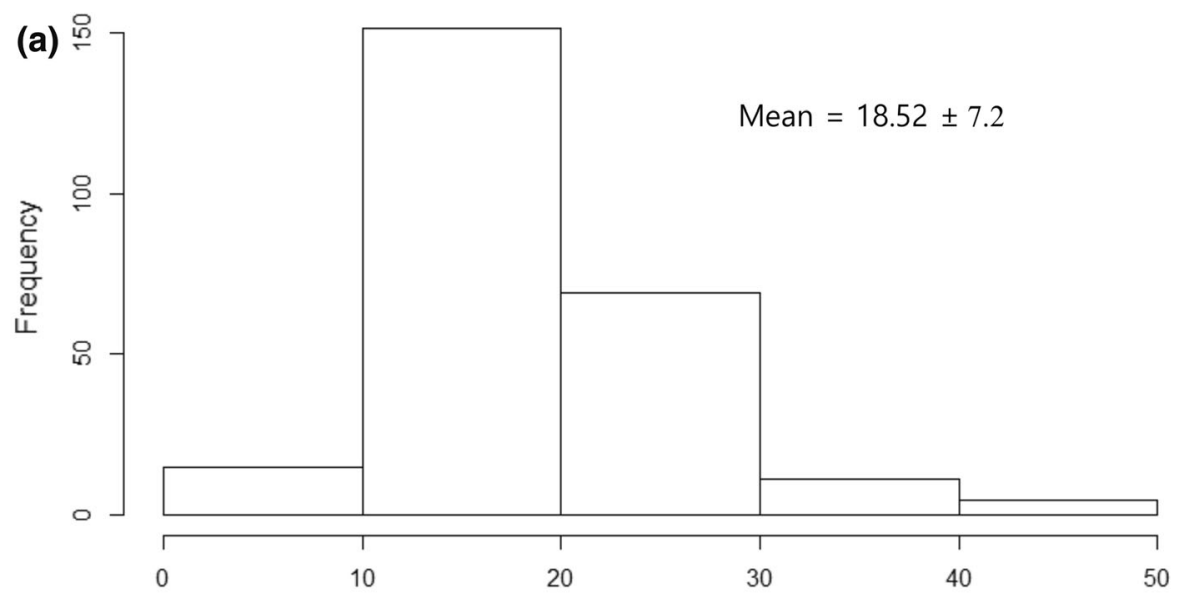

Rutin mg/100 g DW

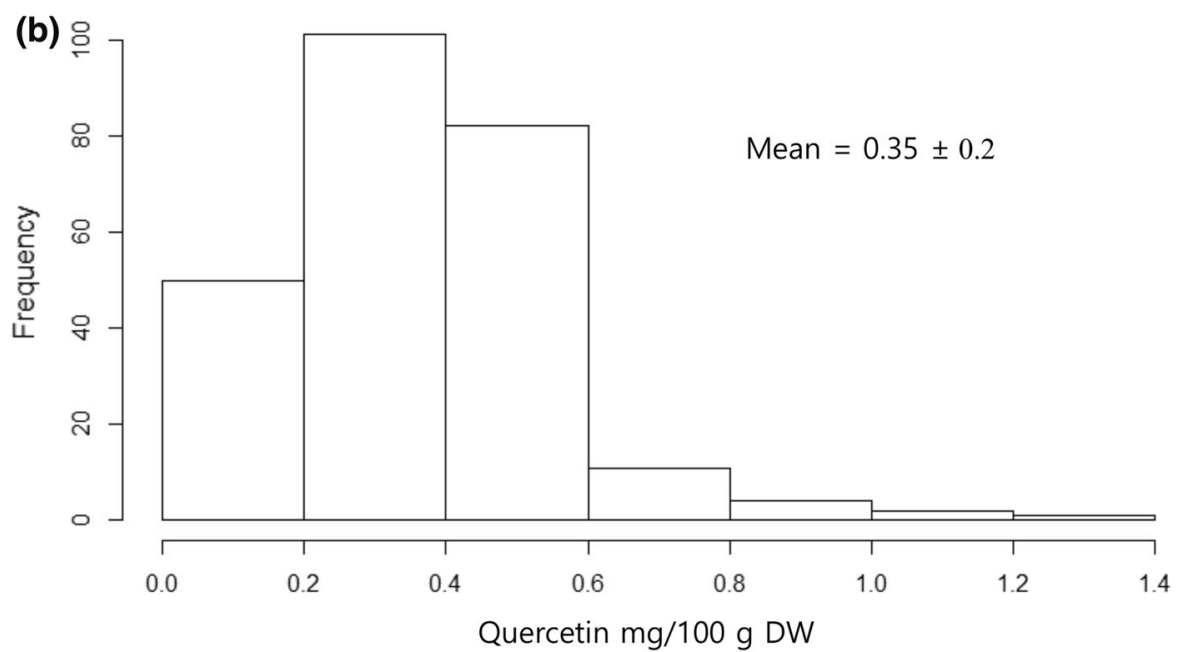

Fig. 2 Frequency distribution of flavonoid components in 251 accessions of common buckwheat (Fagopyrum esculentum): a rutin content, b quercetin content 
Table 3 Ranges and means of agronomic traits and the content of rutin and quercetin in 251 common buckwheat (Fagorpyrum esculentum) germplasm based on collecting countries

\begin{tabular}{|c|c|c|c|c|c|c|c|}
\hline Country $^{a}$ & $\mathrm{n}$ & & $\begin{array}{l}\text { Days to } 50 \% \\
\text { flowering }\end{array}$ & $\begin{array}{l}\text { Days to } 80 \% \\
\text { maturity }\end{array}$ & $\begin{array}{l}\text { 1000-seed weight } \\
(\mathrm{g})\end{array}$ & $\begin{array}{l}\text { Rutin } \\
(\mathrm{mg} / 100 \mathrm{~g} \mathrm{DW})\end{array}$ & $\begin{array}{l}\text { Quercetin } \\
(\mathrm{mg} / 100 \mathrm{~g} \mathrm{DW})\end{array}$ \\
\hline \multirow[t]{2}{*}{ KOR } & 208 & Range & $38-46$ & $75-95$ & $21.0-41.0$ & $8.64-47.86$ & $0-1.15$ \\
\hline & & Mean & 38 & 90 & $25.71 \pm 0.05$ & $17.76 \pm 1.02$ & $0.34 \pm 0.04$ \\
\hline \multirow[t]{2}{*}{ JPN } & 10 & Range & - & $73-94$ & $24.7-42.0$ & $19.24-38.22$ & $0.22-0.70$ \\
\hline & & Mean & 38 & 84 & $31.00 \pm 0.07$ & $26.60 \pm 0.96$ & $0.44 \pm 0.05$ \\
\hline \multirow[t]{2}{*}{ RUS } & 9 & Range & - & $75-94$ & $22.7-35.0$ & $14.68-38.96$ & $0-1.05$ \\
\hline & & Mean & 38 & 81 & $29.85 \pm 0.07$ & $23.17 \pm 1.10$ & $0.46 \pm 0.04$ \\
\hline \multirow[t]{2}{*}{$\mathrm{CHN}$} & 6 & Range & - & $73-88$ & $23.7-34.3$ & $8.75-19.61$ & $0-0.91$ \\
\hline & & Mean & 38 & 83 & $27.70 \pm 0.07$ & $13.78 \pm 0.93$ & $0.44 \pm 0.17$ \\
\hline \multirow[t]{2}{*}{ PAK } & 4 & Range & - & $88-95$ & $25.0-30.0$ & $12.35-17.66$ & $0.30-0.55$ \\
\hline & & Mean & 38 & 92 & $26.42 \pm 0.03$ & $14.91 \pm 0.43$ & $0.37 \pm 0.02$ \\
\hline \multirow[t]{2}{*}{ UKN } & 4 & Range & - & $73-95$ & $25.3-30.0$ & $17.35-22.36$ & $0-0.52$ \\
\hline & & Mean & 38 & 83 & $27.17 \pm 0.05$ & $22.92 \pm 1.12$ & $0.25 \pm 0.03$ \\
\hline \multirow[t]{2}{*}{ CZE } & 3 & Range & - & $75-82$ & $28.7-32.7$ & $21.39-46.75$ & $0.38-0.69$ \\
\hline & & Mean & 38 & 80 & $31.11 \pm 0.04$ & $36.60 \pm 0.76$ & $0.53 \pm 0.02$ \\
\hline \multirow[t]{2}{*}{ IND } & 3 & Range & $38-45$ & $88-95$ & $23.7-25.7$ & $7.22-14.20$ & $0.24-0.33$ \\
\hline & & Mean & 40 & 92 & $24.67 \pm 0.06$ & $10.42 \pm 0.88$ & $0.53 \pm 0.02$ \\
\hline \multirow[t]{2}{*}{ BLR } & 1 & Range & - & - & - & $45.54 \pm 1.45$ & $1.22 \pm 0.59$ \\
\hline & & Mean & 38 & 88 & $32.0 \pm 0.10$ & & \\
\hline \multirow[t]{2}{*}{ BTN } & 1 & Range & - & - & - & $25.80 \pm 0.58$ & $0.53 \pm 0.07$ \\
\hline & & Mean & 38 & 82 & $22.3 \pm 0.58$ & & \\
\hline \multirow[t]{2}{*}{ CAN } & 1 & Range & - & - & - & $14.47 \pm 1.85$ & $0.35 \pm 0.1$ \\
\hline & & Mean & 38 & 80 & $35.3 \pm 0.58$ & & \\
\hline \multirow[t]{2}{*}{ NPL } & 1 & Range & - & - & - & $17.45 \pm 0.56$ & $0.31 \pm 0.02$ \\
\hline & & Mean & 38 & 88 & $33.3 \pm 0.58$ & & \\
\hline \multirow[t]{2}{*}{ Total } & 251 & Range & $38-46$ & $73-95$ & $21.0-42.0$ & $7.22-47.86$ & $0-1.22$ \\
\hline & & Mean & 38 & 89 & $26.3 \pm 0.05$ & $18.52 \pm 1.00$ & $0.35 \pm 0.04$ \\
\hline \multirow[t]{2}{*}{ Control } & 2 & Range & - & $84-88$ & $28.0-32.7$ & $11.64-17.82$ & $0.29-0.36$ \\
\hline & & Mean & 41 & 86 & $30.3 \pm 0.03$ & $14.73 \pm 0.56$ & $0.32 \pm 0.08$ \\
\hline
\end{tabular}

${ }^{a}$ BLR, Belarus; BTN, Bhutan; CAN, Canada; CHN, China; CZE, Czech Republic; IND, India; JPN, Japan; KOR, Korea; NPL, Nepal; PAK, Pakistan; RUS, Russia; UKN, Ukraine

stems was higher than that $(17.96 \mathrm{mg} / 100 \mathrm{~g} \mathrm{DW})$ of germplasm with red-colored stems. Similarly, the mean quercetin content $(0.36 \mathrm{mg} / 100 \mathrm{~g} \mathrm{DW})$ of germplasm with red stems was higher than that $(0.30 \mathrm{mg} / 100 \mathrm{~g} \mathrm{DW})$ of germplasm with pale green stems. The rutin content of germplasm with redcolored stem ranged from 7.22 to $47.86 \mathrm{mg} / 100 \mathrm{~g}$ DW, whereas that of germplasm with pale green stem color ranged from 8.64 to $46.75 \mathrm{mg} / 100 \mathrm{~g}$ DW (Fig. 3a). Similarly, the quercetin content of germplasm with red stem color ranged from 0 to $1.15 \mathrm{mg} /$
$100 \mathrm{~g} \mathrm{DW}$, whereas that of germplasm with pale green stem color ranged from 0 to $1.22 \mathrm{mg} / 100 \mathrm{~g} \mathrm{DW}$ (Fig. 3b). Typically, the basal stems of buckwheat are red or pink, depending on the presence of anthocyanin. Previously, Sytar et al. (2014) demonstrated an association between the pink color of different parts of buckwheat plants and anthocyanin content, which was also found to be associated with rutin content. Consistently, Fang et al. (2019) reported that the selection of buckwheat germplasm for pink-colored seedlings is associated with high rutin content. Plants 
with dark red stem color have been found to contain higher rutin content than plants with red-green or green-red stems (Klykov et al. 2016), thereby indicating that green stem color in buckwheat might be attributable to a lack of relevant enzymes in the
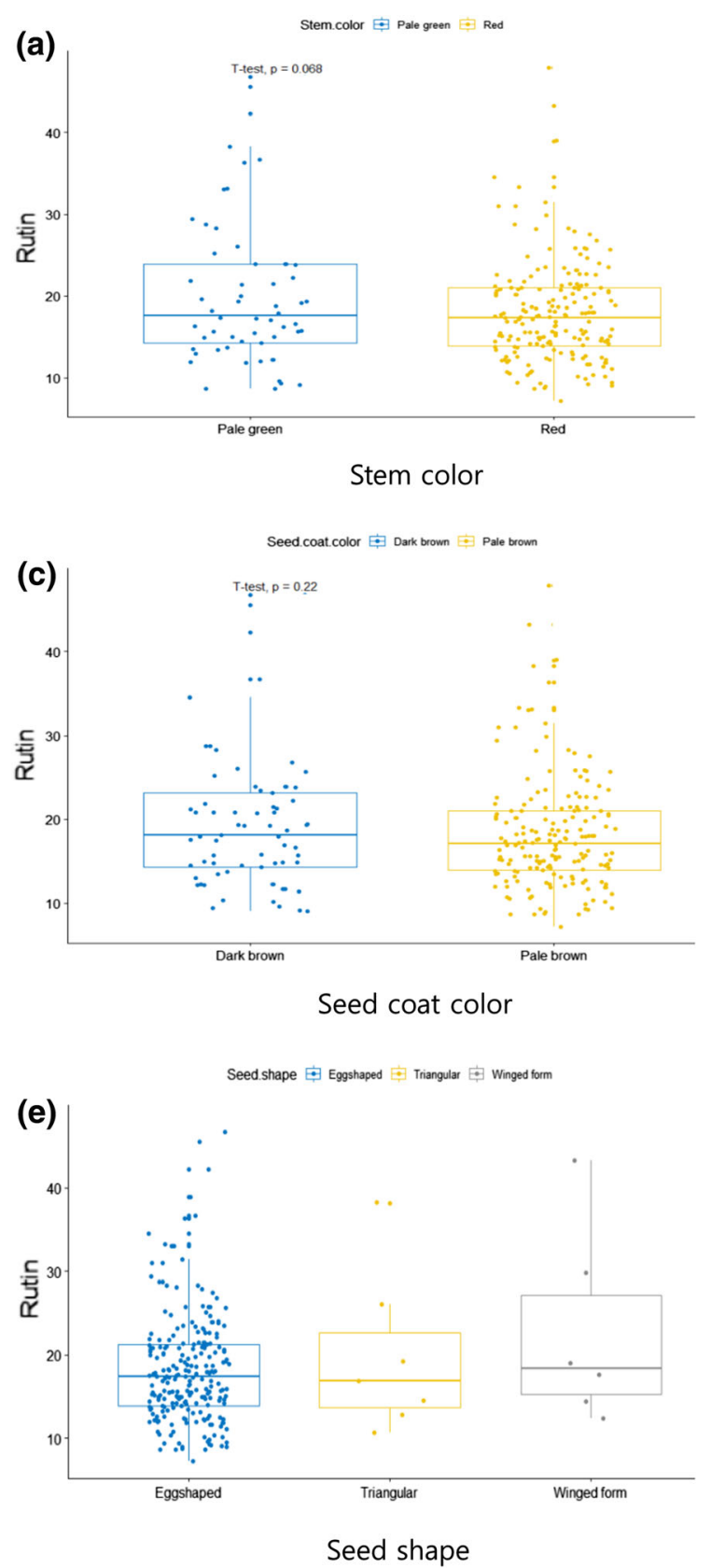

anthocyanin biosynthetic pathway (Matsuri et al. 2008).

Although we found no significant associations between mean rutin content and seed coat color in germplasm with dark brown and pale brown seed coat color, we did detect significant differences with
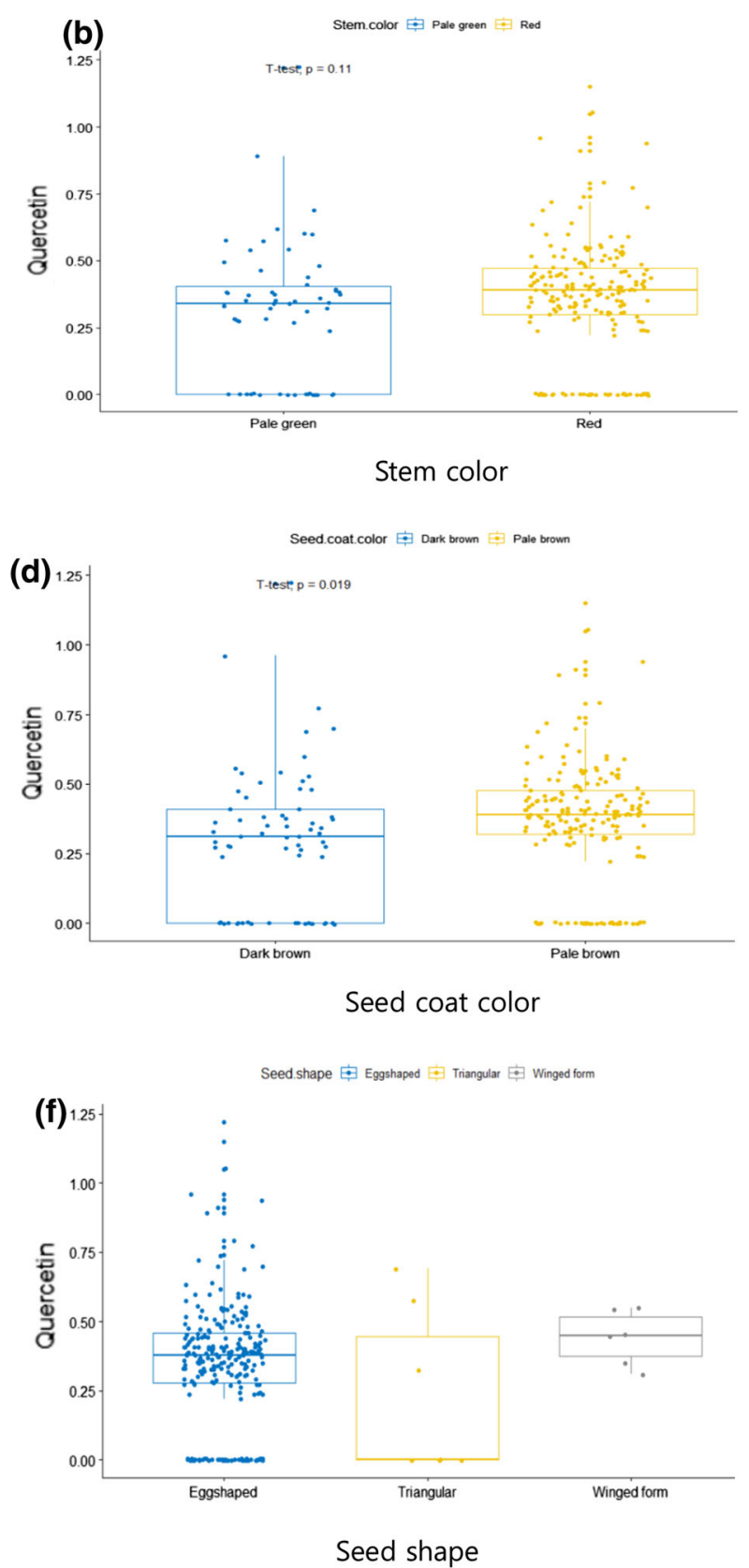

Fig. 3 Diversity in morphological traits of common buckwheat (Fagopyrum esculentum) germplasms associated with the content of rutin and quercetin 
respect to quercetin content. Germplasm with dark brown seed coat color had a higher mean content of rutin $(19.49 \mathrm{mg} / 100 \mathrm{~g}$ DW) than germplasm with pale brown seed coat color. The rutin and quercetin content in germplasm with pale brown seed coat color ranged from $7.22-47.86$ to $0-1.15 \mathrm{mg} / 100 \mathrm{~g} \mathrm{DW}$, respectively. Similarly, the rutin and quercetin content in germplasm with dark brown seed coat color ranged from $9.01-46.75$ to $0-1.22 \mathrm{mg} / 100 \mathrm{~g} \mathrm{DW}$, respectively (Fig. 3c, d). Recently, Yu et al. (2019) reported the highest content of rutin and quercetin in dark gray tartary buckwheat seed followed by dark brown, graybrown and brown. Although it has previously been established that the flavonoid content in seeds is closely related to seed color and seed shape (Hou et al. 2017), in the present study, we failed to detect any significant differences in the mean rutin and quercetin content of germplasm possessing ovate, triangular, or winged-form seeds. The germplasm with winged-form seeds showed the highest mean rutin content (22.77 mg/100 g DW), followed by germplasm with triangular seeds (19.77 mg/100 g DW). Furthermore, the rutin and quercetin content in germplasm with ovate seeds ranged from $7.22-47.86$ to $0-1.22 \mathrm{mg} /$ $100 \mathrm{~g} \mathrm{DW}$, which are higher than the content in germplasm with seeds of other shapes (Fig. 3e, f). Previously, a wide range of variation in the rutin content of tartary buckwheat germplasm has been observed, with gray-colored seeds having higher rutin content than black- and brown-colored seed, and slender seeds having a higher rutin content than notched and round seeds (Park et al. 2004; Sytar et al. 2016; Yu et al. 2019).

Additionally, several studies conducted on other major crop plants have also revealed an association between the seed color and phenolic components (Zhang et al. 2010; Shao et al. 2011; Wang et al. 2015). Although higher flavonoid content was reported in the seed coats than in the embryos of soybean and rice (Bordiga et al. 2014; Min et al. 2015), it has been emphasized that the type and quantity of flavonoids in seed coats and embryos may be related to plant genotype (Hou et al. 2017). Furthermore, Shen et al. (2009) and Shao et al. (2014) found that black- and red-colored rice grains contain higher flavonoid content than white-colored grains. Similarly, the bluecolored grains of barley germplasm have been shown to have higher mean levels of phenolic components than germplasm with purple- and black-colored grains
(Siebenhandl-Ehn et al. 2011), and the blue- and purple-colored grains of barley germplasm have been shown to higher mean phenolic content than blackgrain barley (Kim et al. (2007). In rice, the pigmented bran contains larger amounts of soluble phenolics than non-pigmented rice bran (Ghasemzadeh et al. 2018). Likewise, a wide range for total phenolic content has also been detected among sorghum germplasm differing in grain color, with higher phenolic content being found in pigmented grains Lopez-Martinez et al. (2009) and $\mathrm{Hu}$ and $\mathrm{Xu}$ (2011). These results indicate that variation in seed color is closely associated with phenolic content.

In addition to seed coat color and seed shape, grain size also has a significant effect on the content of phenolic compounds, with small grains tending to contain higher levels of phenolic compounds than medium and large seeds. This is illustrated by the small seeds of tartary buckwheat that have with small seeds, contains higher flavonoid content that the large seeds of common buckwheat, and might be explained by the fact that phenolic compounds are more condensed in smaller grains (Kim et al. 2012).

With respect to agronomic traits, we failed to detect any significant differences in the rutin and quercetin content of germplasm taking 38-40, 41-43, and 44-46 days to reach $50 \%$ flowering (Fig. 4a, b). In contrast, we observed significant differences in the rutin content of germplasm taking 73-80, 81-90, and 91-95 days to reach maturity, although no similar significant differences were found with respect to quercetin content. The highest mean rutin content was found in early-maturing (73-80 days) followed by intermediate- (81-90 days) and late-maturing ( $>91$ days) accessions (Fig. 4c, d). We also detected significant differences in rutin and quercetin content with respect to TSW, with the highest mean rutin content (23.94 mg/100 g DW) being found in germplasm with a TSW $>35 \mathrm{~g}$, although only $1 \%$ of the accessions evaluated had these high seed weights. Accessions with TSW of between 20 and $25 \mathrm{~g}$ accounted for the highest percentage of germplasm (48\%), and these were characterized by rutin content ranging from 8.69 to $47.86 \mathrm{mg} / 100 \mathrm{~g} \mathrm{DW}$. These were followed by the $44 \%$ of germplasm with TSW of between 26 and $30 \mathrm{~g}$, which had rutin content ranging from 7.22 to $46.75 \mathrm{mg} / 100 \mathrm{~g} \mathrm{DW}$ (Fig. 4e, f). 

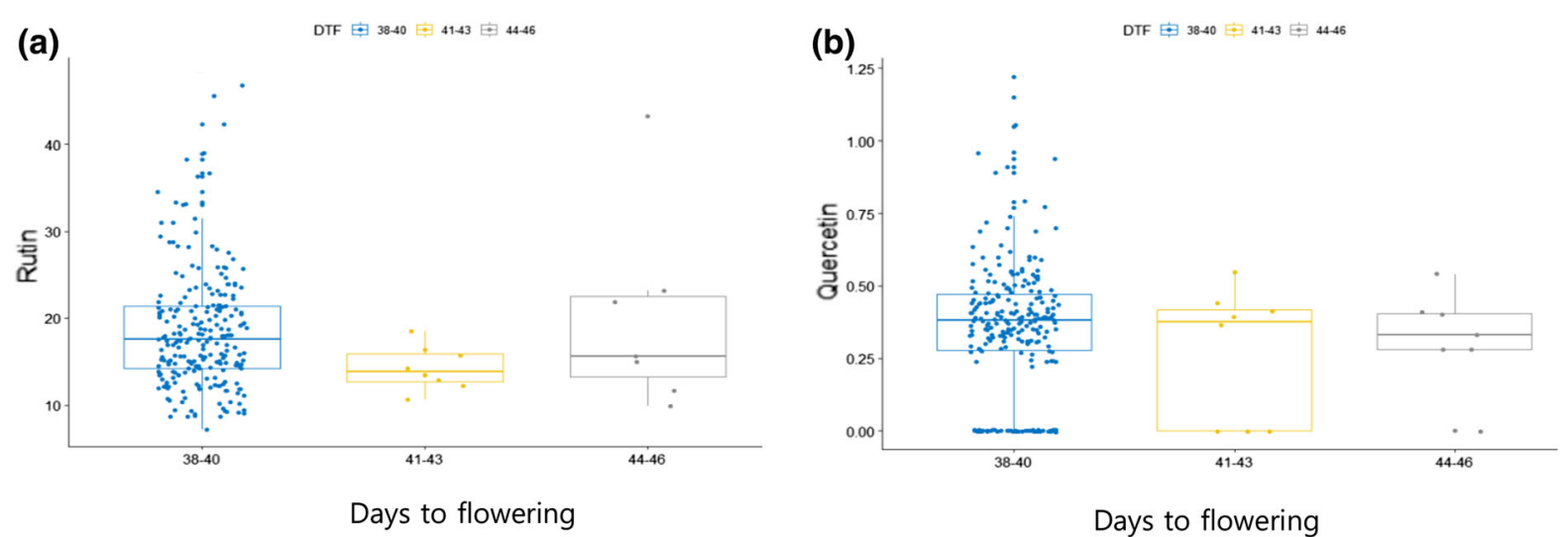

Days to flowering
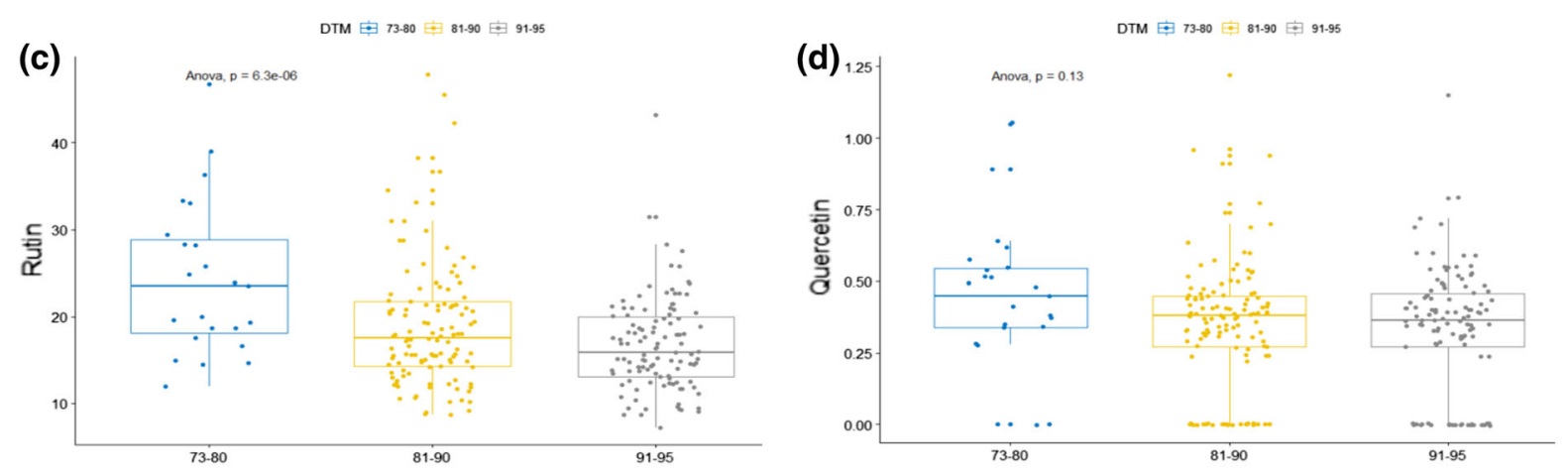

Days to maturity

\section{Days to maturity}
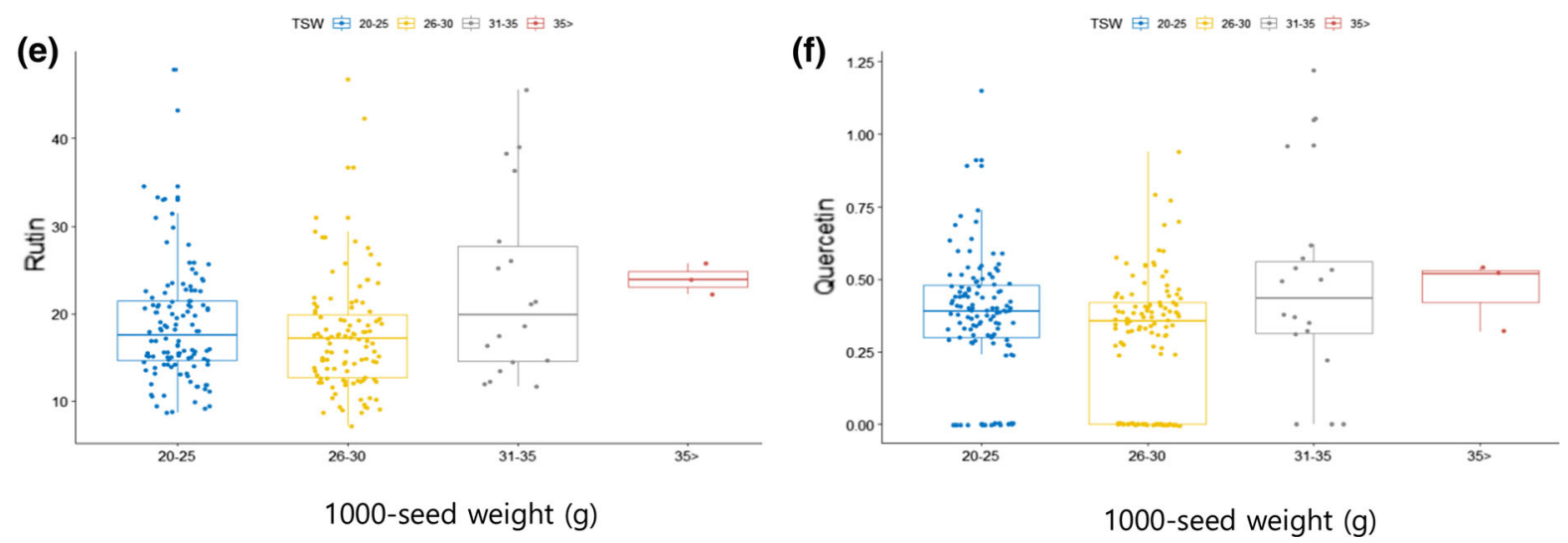

Fig. 4 Diversity in agronomic traits of common buckwheat (Fagopyrum esculentum) germplasms associated with the content of rutin and quercetin

\section{Correlation analysis}

Correlation analysis (Fig. 5) revealed a significant positive correlation between the number of days to flowering and the number of days to reaching maturity and a significant negative correlation between the number of days to flowering and TSW. These results are in line with the findings of Kapoor et al. (2018), who reported similar positive and negative correlations in common buckwheat germplasm. This could be due to the early transition from vegetative growth to reproductive development, which is characterized by less vegetative growth. In agreement, Li et al. (2012) found that late flowering was associated with 
increased plant height and higher yields. We also detected negative and non-significant correlations between the number of days to flowering and rutin and quercetin content. Earlier, Oomah et al. (1996) reported less rutin content in early flowering genotypes than that of late cultivars with late flowering. Furthermore, the number of days taken to reach maturity was found to be significantly negatively correlated with TSW, rutin content, and quercetin content. The TSW was significantly positively correlated with rutin content but non-significantly and positively with quercetin content. However, the correlation between TSW and rutin content was not strong to any considerable degree, which is consistent with the findings of Brunori and Vegvari (2007) who also reported a weak correlation between grain yield and rutin content. Rutin content was found to be significantly positively correlated with quercetin content, which might be predicted given the fact that rutin and quercetin are the major flavonoids in buckwheat seeds (Bai et al. 2015). A linear and positive correlation has likewise been detected in the seed rutin and quercetin content of tartary buckwheat germplasm (Yu et al. 2019).

Although buckwheat seeds generally contain high levels of rutin and low quercetin content, during the bread-making process the levels of these two flavonoids are reversed due to the conversion of rutin to quercetin, this process depends upon the rutin-degrading enzyme rutinase found in seeds, and imparts a bitter taste in buckwheat-derived food products (Yasuda and Nakagawa 1994). This bitter taste can, however, be eliminated by the hot water treatment of buckwheat seeds at temperatures in excess of $90{ }^{\circ} \mathrm{C}$ rutinase activity. However, there are also a number of non-bitter buckwheat varieties in which rutin remains under graded (Suzuki et al. 2014).

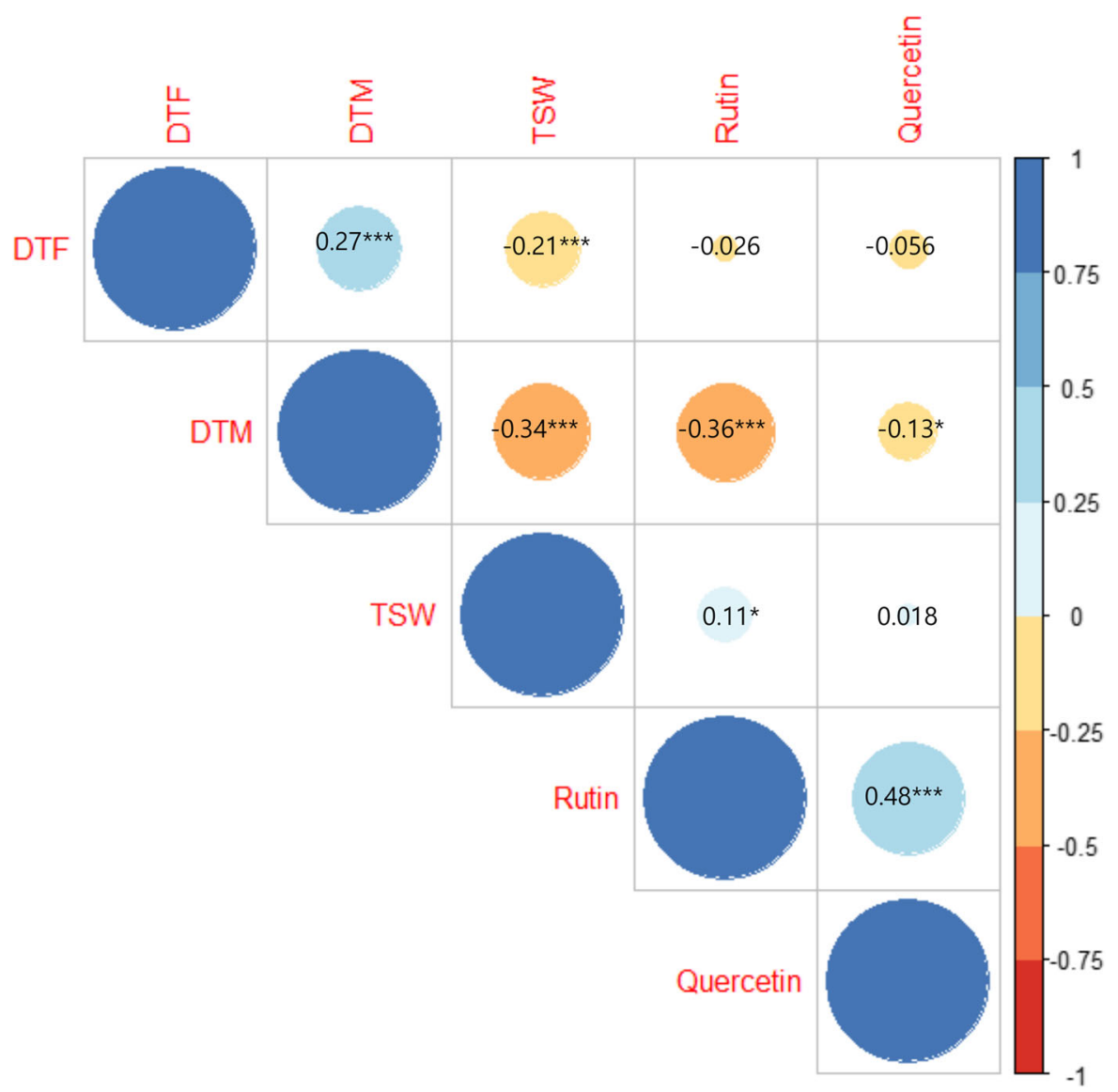

Fig. 5 Correlation between the agronomic traits and flavonoid components (rutin and quercetin) of common buckwheat (Fagopyrum. esculentum) germplasms 
Table 4 Eigenvalues, percentage of variance, and loadings of different principal components of common buckwheat (Fagopyrum esculentum) accessions

\begin{tabular}{lcccrr}
\hline Traits & PC1 & PC2 & PC3 & \multicolumn{1}{c}{ PC4 } & \multicolumn{1}{c}{ PC5 } \\
\hline TSW $^{\text {a }}$ & 0.383 & -0.469 & 0.493 & 0.621 & 0.072 \\
DTF & -0.294 & 0.485 & 0.785 & -0.048 & -0.244 \\
DTM & -0.552 & 0.249 & -0.175 & 0.612 & 0.479 \\
Rutin & 0.536 & 0.432 & 0.136 & -0.191 & 0.687 \\
Quercetin & 0.419 & 0.544 & -0.302 & 0.449 & -0.485 \\
Eigenvalue & 1.83 & 1.25 & 0.85 & 0.65 & 0.43 \\
Variance (\%) & 36.50 & 25.00 & 16.91 & 12.97 & 8.63 \\
\hline
\end{tabular}

${ }^{\mathrm{a}} \mathrm{TSW}, 1000$-seed weight; DTM, days to $50 \%$ flowering; DTM, days to $80 \%$ maturity

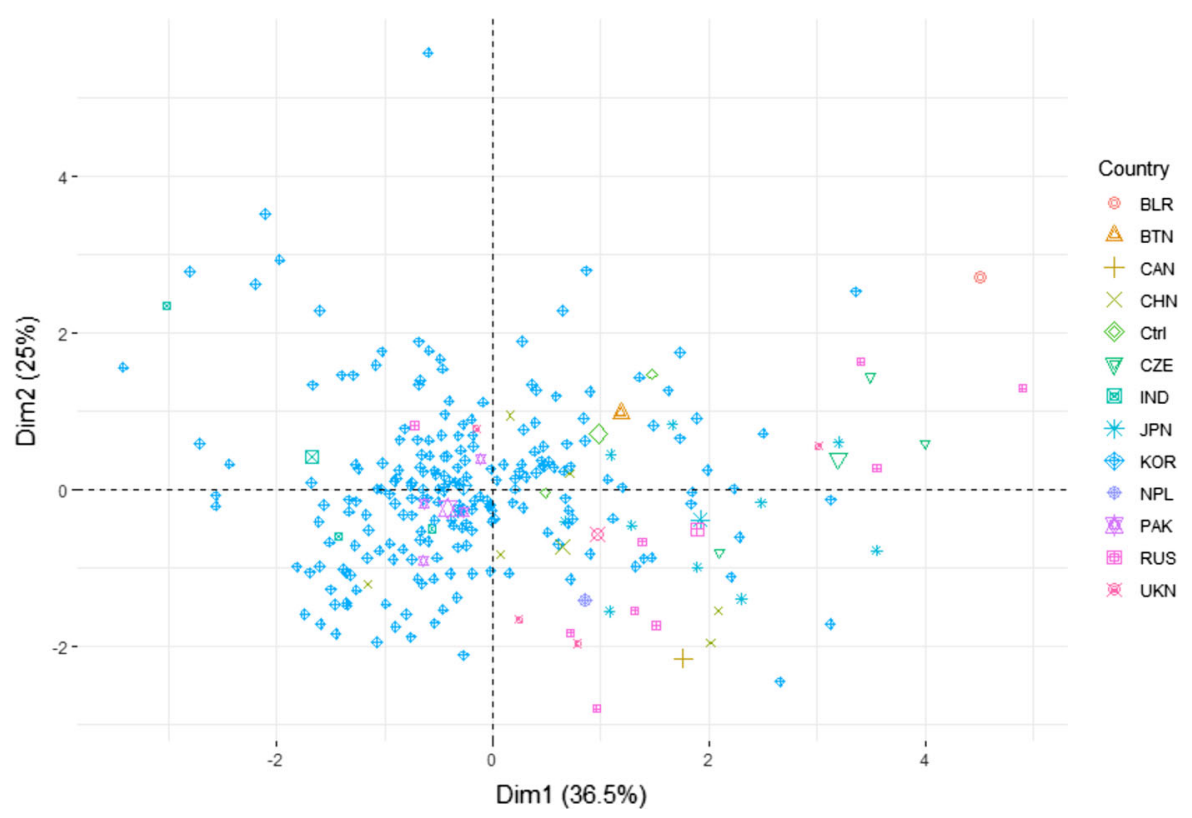

Fig. 6 Principal component analysis of 251 common buckwheat (Fagopyrum esculentum) germplasms accessions

Principal component analysis (PCA)

In an attempt to distinguish the common buckwheat germplasm based on their country of collection, PCA was performed based on the correlation matrix. PCA is used to analyze multidimensional data sets and to identify putative variables that provide maximum variability (Steiner et al. 2009). It also provides insights into different clusters and certain valuable traits, making it possible for breeders to identify distinct features of interest (Hussain 2015). The loadings, eigenvalues and the percentage of variance for PCA are presented in Table 4. In the present study, we found that the first two principal components (PC1 and PC2), with an eigenvalue greater than 1, accounted for $36.5 \%$ and $25 \%$ of the total variability, respectively. Rutin and quercetin were the main contributors to the variability to $\mathrm{PC} 1$, whereas Quercetin, days to flowering and Rutin were the major contributor to PC2. The number of days to flowering and TSW were found to be the main contributors to PC3 (Table 4). According to the PCA biplot (Fig. 6), a high level of heterogeneity was observed among germplasm based on their agronomic traits and flavonoid content. The germplasm accessions with high rutin and quercetin contents were placed on the 
Table 5 Promising common buckwheat (Fagopyrum esculentum) accessions with high rutin and quercetin content

\begin{tabular}{|c|c|c|}
\hline Trait & Characteristics & Accession number \\
\hline $\begin{array}{l}\text { Early } \\
\text { maturity }\end{array}$ & Below 80 days & $\begin{array}{l}225055\left(\mathrm{UKN}^{\mathrm{a}}\right), 250624 \text { (CHN), } 28844 \text { (JPN), } 179844 \text { (RUS), } 108885 \text { (KOR), } 250622 \text { (CZE), } \\
261921 \text { (JPN), } 104769 \text { (KOR), } 278145 \text { (RUS), } 104551 \text { (KOR), } 101282 \text { (KOR), } 278144 \text { (RUS), } \\
179843 \text { (RUS), } 261925 \text { (CHN) }\end{array}$ \\
\hline $\begin{array}{c}\text { 1000-seed } \\
\text { weight }\end{array}$ & $\geq 35 \mathrm{~g}$ & 200686 (RUS), 302264 (CAN), 250614 (KOR), 235375 (KOR), 221968 (JPN) \\
\hline Rutin & $\begin{array}{l}\geq 35 \mathrm{mg} / \\
100 \mathrm{~g} \mathrm{DW}\end{array}$ & $\begin{array}{l}264173 \text { (KOR), } 199286 \text { (RUS), } 250617 \text { (JPN), } 261923 \text { (JPN), } 179843 \text { (RUS), } 288929 \text { (CZE), } \\
185707 \text { (KOR), } 179846 \text { (BLR), } 250622 \text { (CZE), } 100801 \text { (KOR) }\end{array}$ \\
\hline Quercetin & $\begin{array}{l}\geq 1 \mathrm{mg} / \\
100 \mathrm{~g} \mathrm{DW}\end{array}$ & 179843 (RUS), 103836 (KOR), 179846 (BLR) \\
\hline
\end{tabular}

upper right side plot, whereas the germplasm accessions with high TSW were placed on the lower right side plot. The control cultivars were placed at the center of PCA biplot. This information could be useful for plant breeders to select the most variable characters and promising accessions for buckwheat improvement.

\section{Conclusion}

The buckwheat accessions evaluated in this study were found to show considerable diversity with respect to morphological traits and flavonoid content as well as region from which accessions were collected. The detail of agro morphological traits and the content of rutin and quercetin for each accession are given as Supplemental Table S1. We believe that the findings of this study will provide a valuable basis for future buckwheat breeding programs and the development of high-yielding buckwheat cultivars for spring cultivation. We selected 32 promising accessions, which could be used as useful breeding material to improve the grain yield and content of rutin and quercetin in existing buckwheat cultivars (Table 5). The selected accession will be further evaluated for grain yield and flavonoid content under spring and fall cultivation. These accessions include 14 accessions with early maturity (below 80 days), 5 accessions with highest TSW ( $\geq 35 \mathrm{~g}$ ), 10 with highest rutin content $(\geq 35 \mathrm{mg} / 100 \mathrm{~g} \mathrm{DW})$ and 3 with highest quercetin content $(\geq 1 \mathrm{mg} / 100 \mathrm{~g} \mathrm{DW})$. From the perspective of future studies, selected germplasm with high rutin content could be characterized for low rutinase activity to minimize the degradation of rutin molecules during dough fermentation, which is responsible for the bitter taste that characterizes buckwheat-derived food products.

Acknowledgements This study was supported by the "Research Program for Agricultural Science and Technology Development (Project No. PJ012478)" of the National Institute of Agricultural Sciences, Rural Development Administration.

Author contributions Substantial contributions to the conception or design of the work by DYH, OS and M-CL; Drafting the work or revising it critically for important intellectual content by MR, HY; Final approval of the version to be published by Y-MC; Agreement to be accountable for all aspects of the work in ensuring that questions related to the accuracy or integrity of any of the work are appropriately investigated and resolved by SL and Y-MC.

\section{Compliance with ethical standards}

Conflict of interest The authors declare that they have no financial or competing interests.

Open Access This article is licensed under a Creative Commons Attribution 4.0 International License, which permits use, sharing, adaptation, distribution and reproduction in any medium or format, as long as you give appropriate credit to the original author(s) and the source, provide a link to the Creative Commons licence, and indicate if changes were made. The images or other third party material in this article are included in the article's Creative Commons licence, unless indicated otherwise in a credit line to the material. If material is not included in the article's Creative Commons licence and your intended use is not permitted by statutory regulation or exceeds the permitted use, you will need to obtain permission directly from the copyright holder. To view a copy of this licence, visit http://creativecommons.org/licenses/by/4.0/. 


\section{References}

Arduini I, Masoni A, Mariotti M (2016) A growth scale for the phasic development of common buckwheat. Acta Agric Scand Sect B Soil Plant Sci 66:215-228

Bai CZ, Feng ML, Hao XL, Zhong QM, Tong LG, Wang ZH (2015) Rutin, quercetin, and free amino acid analysis in buckwheat (Fagopyrum) seeds from different locations. Genet Mol Res 14:19040-19048

Baniya BK, Dongol DMS, Dhungel NR (1995) Further characterization and evaluation of Nepalese buckwheat (Fagopyrum spp.) landraces. In: Proceedings of the 6th international symposium on buckwheat, pp 295-304

Bobkov S (2016) Biochemical and technological properties of buckwheat grains. In: Zhou M, Kreft I, Woo S-H, Chrungoo N, Wieslander G (eds) Molecular breeding and nutritional aspects of buckwheat. Elsevier Science, London, pp 423-440

Bordiga M, Gomez-Alonso S, Locatelli M, Travaglia F, Coisson JD, Hermosin-Gutierrez I et al (2014) Phenolics characterization and antioxidant activity of six different pigmented Oryza sativa cultivars grown in piedmont (Italy). Food Res Int 65:282-290

Brunori A, Vegvari G (2007) Rutin content of the grain of buckwheat (Fagopyrum esculentum Moench. and Fagopyrum tataricum Gaertn.) varieties grown in southern Italy. Acta Agron Hung 55:265-272

Brunori A, Sandor G, Xie H, Baviello G, Nehiba B, Rabnecz G, Vegari G (2009) Rutin content of the grain of 22 buckwheat (Fagopyrum esculentum Moench and Fagopyrum tataricum Gaertn.) varieties grown in Hungary. Eur J Plant Sci Biotechnol 3:62-65

Brunori A, Baviello G, Zannettino C, Corsini G, Sandor G, Vegvari G (2010) The use of tartary buckwheat whole flour for bakery products: recent experience in Italy. Annals of the University Dunarea de Jos Galati Fascicle V1? Food Technol 34:33-38

Bystricka J, Musilova J, Tomas J, Vollmannova A, Lachman J, Kavalcova P (2014) Changes of polyphenolic substances in the anatomical parts of buckwheat (Fagopyrum esculentum Moench.) during its growth phases. Foods 3:558-568

Cepková PH, Janovská D, Stehno Z (2009) Assessment of genetic diversity of selected tartary and common buckwheat accessions. Span J Agric Res 7:844-854

Chauhan RS, Gupta N, Sharma SK, Rana JC, Sharma TR, Jana S (2010) Genetic and genome resources in buckwheat-present status and future perspectives. In: Dobranszki J (Ed) Buckwheat 2. Eur J Plant Sci Biotechnol 4:33-44

Chen QF, Huang XY, Li HY, Yang LJ, Cui YS (2018) Recent progress in perennial buckwheat development. Sustainability 10:536

Dwivedi SL, Ceccarelli S, Blair MW, Upadhyaya HD, Are AK, Ortiz R (2016) Landrace germplasm for improving yield and abiotic stress adaptation. Trends Plant Sci 21:31-42

Fabjan N, Rode J, Košir IJ, Wang Z, Zhang Z, Kreft I (2003) Tartary buckwheat (Fagopyrum tataricum Gaertn.) as a source of dietary rutin and quercetin. J Agric Food Chem 51:6452-6455

Fang Z, Hou Z, Wang S, Liu Z, Wei S, Zhang Y et al (2019) Transcriptome analysis reveals the accumulation mechanism of anthocyanins in buckwheat (Fagopyrum esculentum Moench) cotyledons and flowers. Int J Mol Sci 20:1493

Ferreira RR, Varisi VA, Meinhardt LW, Lea PJ, Azevedo RA (2005) Are high lysine cereal crops still a challenge? Braz J Med Biol Res 38:985-994

Ganeshpurkar A, Saluja AK (2017) The pharmacological potential of rutin. Saudi Pharm J 25:149-164

Ghasemzadeh A, Karbalaii MT, Jaafar HZE, Rahmat A (2018) Phytochemical constituents, antioxidant activity, and antiproliferative properties of black, red, and brown rice bran. BMC Chem 12:17

Ghiasi M, Azadnia A, Arabieh M, Zahedi M (2012) Protective effect of rutin (vitamin p) against heme oxidation: a quantum mechanical approach. Comput Theor Chem 996:28-36

Grahic J, Dikic M, Gadzo D, Uzunovic M, Okic A, Kurtovic M et al (2016) Analysis of agronomic practices of buckwheat produces in Bosnia and Herzegovina. Works Fac Agric Food Sci Univ Sarajevo 66:21-30

Grubben GJH, Siemonsma JS (1996) Fagopyrum esculentum Moench. In: Grubben GJH, Partohardjono S (eds) Plant resources of South-East Asia No. 10. Cereals. Backhuys Publishers, Leiden, pp 95-99

Gupta N, Naik PK, Chauhan RS (2012) Differential transcript profiling through cDNA-AFLP showed the complexity of rutin biosynthesis and accumulation in seeds of a nutraceutical food crop (Fagopyrum spp.). BMC Genom $13: 231$

Hou M, Mu G, Zhang Y, Chi S, Yang X, Liu L (2017) Evaluation of total flavonoid contents and analysis of related EST-SSR in Chinese peanut germplasm. Crop Breed Appl Biotechnol 17:221-227

Hu QP, Xu JG (2011) Profiles of carotenoids, anthocyanins, phenolics, and antioxidant activity of selected color waxy corn grains during maturation. J Agric Food Chem 59:2026-2033

Hussain I (2015) Agro-morphological, biochemical and molecular characterization of buckwheat Fagopyrum esculentum (Moench) in Baltistan. Quaid-i-Azam University, Islamabad

Hyun DY, Rauf M, Lee S, Ko HC, Oh S, Lee MC et al (2018) Comparison of growth characteristics and flavonoids content by different cultivation seasons in buckwheat germplasm. Korean J Plant Res 31:489-497

International Seed Testing Association (2019) Thousand-seed weight (TSW) determination. In: International rules for seed testing. ISTA Switzerland, pp 1-2

Iwata H, Imon K, Tsumura Y, Ohsawa R (2005) Genetic diversity among Japanese indigenous common buckwheat (Fagopyrum esculentum) cultivars as determined from amplified fragment length polymorphism and simple repeat markers and quantitative agronomic traits. Genome 48:367-377

Jinfeng G, Shouqiang A, Xiaoli G, Dongli G (2010) Effect of sowing at different time on flavonoid content of buckwheat. In: Proceedings of the 10th international symposium on buckwheat, pp 338-342

Joshi BD, Rana RS (1995) Buckwheat (Fogopyrum esculentum). In: Williams JT (ed) Cereals and pseudocereals. Champman and Hall, New York, pp 85-127 
Jung GH, Kim SL, Kim MJ, Kim SK, Park JH, Kim CG, Heu S (2015) Effect of sowing time on buckwheat (Fagopyrum esculentum Moench) growth and yield in central Korea. J Crop Sci Biotechnol 18:285-291

Kalinová J, Dadáková E (2006) Varietal and year variation of rutin in common buckwheat (Fagopyrum esculentum Moench). Cereal Res Commun 34:1315-1320

Kalinová JP, Vrchotov N, Tř́ska J (2019) Phenolics levels in different parts of common buckwheat (Fagopyrum esculentum) achenes. J Cereal Sci 85:243-248

Kapoor C, Avasthe RK, Chettri PK, Gopi R, Kalita H, Rana JC (2018) Multivariate analysis to evaluate common and tartary buckwheat germplasm in Sikkim. Indian J Plant Genet Resour 31:134-141

Kim SL, Son YK, Hwang JJ, Kim SK, Hur HS, Park CH (2001) Development and utilization of buckwheat sprouts as a functional vegetables. In; Proceedings of the 8th ISB, pp 653-660

Kim SJ, Kawaharada C, Suzuki T, Saito K, Hashimoto N, Takigawa $S$ et al (2006) Effect of natural light periods on rutin, free amino acid and vitamin $\mathrm{C}$ contents in the sprouts of common (Fagopyrum esculentum Moench) and tartary (F. tataricum Gaertn.) buckwheats. Food Sci Technol Res 12:199-205

Kim MJ, Hyun JN, Kim JA, Park JC, Kim MY, Kim JG et al (2007) Relationship between phenolic compounds, anthocyanins content and anti-oxidant activity in colored barley germplasm. J Agric Food Chem 55:4802-4809

Kim SJ, Zaidul ISM, Suzuki T, Mukasa Y, Hashimoto N, Takigawa $\mathrm{S}$ et al (2008) Comparison of phenolic compositions between common and tartary buckwheat (Fagopyrum) sprouts. Food Chem 110:814-820

Kim EH, Ro HM, Kim SL, Kim HS, Chung IM (2012) Analysis of isoflavones, phenolic, soyasapogenol, and tocopherol compounds in soybean [Glycine max (L.) Merrill] germplasms of different seed weight sand origins. J Agric Food Chem 60:6045-6055

Kiprovski B, Petkovesek MM, Slatnar A, Veberic R, Stampar F et al (2015) Comparison of phenolic profile and antioxidant properties of European Fagopyrum esculentum cultivars. Food Chem 185:41-47

Kitabayashi H, Ujihara A, Hirose T, Minami M (1995) On the genotypic differences for rutin content in tartary buckwheat, Fagopyrum tataricum Gaertn. Breed Sci 45:189194

Klykov AG, Moiseenko LM, Barsukova YN (2016) Biological resources and selection value of species of Fagopyrum Mill. Genus in the Far East of Russia. In: Zhou M, Kreft I, Woo SH, Chrungoo N, Wieslander G (eds) Molecular breeding and nutritional aspects of buckwheat. Elsevier Science, London, pp 51-60

Kreft I, Fabjani N, Germ M (2003) Rutin in buckwheat-protection of plants and its importance for the production of functional food. Fagopyrum 20:7-11

Li SQ, Zhang QH (2001) Advances in the development of functional foods from Buckwheat. Crit Rev Food Sci Nutr 41:451-464

Li C, Kobayashi K, Yoshida Y, Ohsawa R (2012) Genetic analyses of agronomic traits in tartary buckwheat (Fagopyrum tataricum (L.) Gaertn.). Breed Sci 62:303-309
Lopez-Martinez L, Oliart-Ros RM, Valerio-Alfaro G, Lee CH, Parkin KL, Garcia HS (2009) Antioxidant activity, phenolic compounds and anthocyanins content of eighteen strains of Mexican maize. LWT Food Sci Technol 42:1187-1192

Mathesius U (2018) Flavonoid functions in the plants and their interaction with other organisms. Plants 7:30

Matsuri K, Eguchi K, Tetsuka T (2008) A novel gene that diverts the anthocyanin biosynthetic pathway towards the production of pro-anthocyanidins in common buckwheat (Fagopyrum esculentum). Breed Sci 58:143-148

Mazza G, Oomah BD (2005) Buckwheat as a food and feed. In: Abdel-Aaal E, Wood P (eds) Specialty grains for food and Feed. American Association of Cereal Chemists, St. Paul, pp 375-393

McGraw-Hill C (2008) Statistix 8.1 (Analytical Software, Tallahassee, Florida). Maurice/Thomas text (ISBN: 0073402818). Analytical Software, Tallahassee, USA

Min HK, Kim SM, Baek SY, Woo JW, Park JS, Cho ML et al (2015) Anthocyanin extracted from black soybean seed coats prevents autoimmune arthritis by suppressing the development of Th17 cells and synthesis of proinflammatory cytokines by such cells, via Inhibition of NF-kB. PLoS ONE 10:e0138201

Minami M, Kitabayashi H, Nemoto K, Ujihara A (2001) Breeding of high rutin content common buckwheat, "SunRutin". In: Proceedings of the 8th ISB, pp 367-370

Nam TG, Lim YJ, Eom SY (2018) Flavonoid accumulation in common buckwheat (Fagopyrum esculentum) sprout tissues in response to light. Hortic Environ Biotechnol 59:19-27

Omidbaigi R, Mastro GD (2004) Influence of sowing time on the biological behaviour, biomass production, and rutin content of buckwheat (Fagopyrum esculentum Moench). Ital J Agron 8:47-50

Oomah BD, Clayton G, Campbell CG, Mazza G (1996) Effect of cultivar and environment on phenolic acids in buckwheat. Euphytica 90:73-77

Panche AN, Diwan AD, Chandra SR (2016) Flavonoids: an overview. J Nutr Sci 4:1-15

Park CH, Kim YB, Choi YS, Heo K, Kim SL, Lee KC et al (2000) Rutin content in food products processed from groats, leaves, and flowers of buckwheat. Fagopyrum 17:63-66

Park BJ, Park JI, Chang KJ, Park CH (2004) Comparison in rutin content in seed and plant of tartary buckwheat (Fagopyrum tataricum). In: Proceedings of the 9th international symposium on buckwheat. Prague

Park BJ, Park JI, Chang KJ, Park CH (2005) Comparison in rutin content of tartary buckwheat (Fagopyrum tataricum). Korean J Plant Resour 18:246

Podolska G (2016) The effect of habitat conditions and agrotechnical factors on the nutritional value of buckwheat. In: Zhou M, Kreft I, Woo SH, Chrungoo N, Wieslander G (eds) Molecular breeding and nutritional aspects of buckwheat. Elsevier Science, London, pp 283-297

Qin P, Wang Q, Shan F, Hou Z, Ren G (2010) Nutritional composition and flavonoids contents of flour from different buckwheat cultivars. Int J Food Sci Technol 45:951-958 
Raina AP, Gupta V (2015) Evaluation of buckwheat (Fagopyrum species) germplasm for rutin content in seeds. Indian J Plant Physiol 20:167-171

Rout MK, Chrungoo NK (1999) The lysine and methionine rich basic subunit of buckwheat grain legumin: some results of a structural study. Biochem Mol Biol Int 47:921-926

RStudio Team (2019) RStudio: integrated development for R. RStudio, Inc., Boston. http://www.rstudio.com/

Rural Development Administration (2012a) Standard protocol of research method and analysis. Rural Development Administration, Suwon

Rural Development Administration (2012b) Manual on investigation of characteristics for agriculture science and technology. National Institute of Agricultural Sciences, Suwon

Seo JM, Lee DB, Arasu MV, Wu Q, Suzuki T, Yoon YH et al (2013) Quantitative differentiation of phenolic compounds in different varieties of buckwheat cultivars from China, Japan and Korea. J Agric Chem Environ 2:109-116

Shao YF, Jin L, Zhang G, Lu Y, Shen Y, Bao JS (2011) Association mapping of grain color, phenolic contents, flavonoid contents and antioxidant capacity in dehulled rice. Theor Appl Genet 122:1005-1016

Shao Y, Tang F, Huang Y, Xu F, Chen Y, Tong C et al (2014) Analysis of genotype $\times$ environment interactions for polyphenols and antioxidant capacity of rice by association mapping. J Agric Food Chem 62:5361-5368

Shen Y, Jin L, Xiao P, Lu Y, Bao J (2009) Total phenolics, flavonoids, antioxidant capacity in rice grain and their relations to grain color, size and weight. J Cereal Sci 49:106-111

Siebenhandl-Ehn S, Kinner M, Leopold LF, Poppernitsch MB, Prückler M, Wurbs P et al (2011) Hulless Barley-a rediscovered source for functional foods phytochemical profile and soluble dietary fiber content in naked barley varieties and their antioxidant properties. http://cdn. intechopen.com/pdfs-wm/25502.pdf

Steiner JE, Menezes RB, Ricci TV, Oliveira AS, Author's notes (2009) PCA tomography: how to extract information from data cubes. Mon Not R Astron Soc 395:64-75

Suzuki T, Honda Y, Mukasa Y (2005) Effects of UV-B radiation, cold and desiccation stress on rutin concentration and rutin glucosidase activity in tartary buckwheat (Fagopyrum tataricum) leaves. Plant Sci 168:1303-1307
Suzuki T, Morishita T, Mukasa Y, Takigawa S, Yokota S, Ishiguro K, Noda T (2014) Breeding of 'Manten-Kirari', a non-bitter and trace-rutinosidase variety of Tartary buckwheat (Fagopyrum tataricum Gaertn.). Breed Sci 64:344-350

Sytar O, Kosyan A, Taran N, Smetanska I (2014) Anthocyanin as a marker for selection of buckwheat plants with high rutin content. Gesunde Pflanzen 66:165-169

Sytar O, Bresticb M, Zivcak M, Tran LSP (2016) The contribution of buckwheat genetic resources to health and dietary diversity. Curr Genomics 17:193-206

Sytar O, Chrenková M, Ferencová J, Polačiková M, Rajský M, Brestič M (2018) Nutrient capacity of amino acids from buckwheat seeds and sprouts. J Food Nutr Res 75:38-74

Tome D, Bos C (2007) Lysine requirement through the human life cycle. J Nutr 137:1642S-1645S

Vicente O, Boscaiu M (2018) Flavonoids: antioxidant compounds for plant defense and for a healthy human diet. Not Bot Horti Agrobo 46:14-21

Wang Y, Han YP, Zhao X, Li YG, Teng WL, Li DM, Zhang Y, Li WB (2015) Mapping isoflavone QTL with main epistatic and QTL $\times$ environment effect in recombinant inbred lines of soybean. PLoS ONE 10:e0118447

Wiczkowski W, Szawara-Nowak D, Debski H, Mitrus J, Horbowicz M (2014) Comparison of flavonoids profile in sprouts of common buckwheat cultivars and wild tartary buckwheat. Int J Food Sci Technol 49:1977-1984

Yasuda T, Nakagawa H (1994) Purification and characterization of rutin degrading enzymes in tartary buckwheat seeds. Phytochem 37:133-136

Yu S, Tian L (2018) Breeding major cereal grains through the lens of nutrition sensitivity. Mol Plant 11:23-30

Yu JH, Kwon SJ, Choi JY, Ju YH, Roy SK, Lee DG, Park CH, Woo SH (2019) Variation of rutin and quercetin in tartary buckwheat germplasm. Fagopyrum 36:51-65

Zhang MW, Zhang RF, Zhang FX, Liu RH (2010) Phenolic profiles and antioxidant activity of black bran of different commercially available varieties. J Agric Food Chem 58:7580-7587

Publisher's Note Springer Nature remains neutral with regard to jurisdictional claims in published maps and institutional affiliations. 